\title{
Diversidade e Formação Humana Integral: uma relação convergente
}

\author{
Diversity and Integral Human Education: a converging relationship \\ Diversidad y Formación Humana Integral: una relación convergente
}

Recebido: 01/02/2022 | Revisado: 06/02/2022 | Aceito: 06/02/2022 | Publicado: 13/02/2022

\author{
Leonardo Bezerra da Silva \\ ORCID: https://orcid.org/0000-0001-8083-3456 \\ Instituto Federal de Educação, Ciência e Tecnologia do Ceará, Brasil \\ E-mail: leonardo.bezerra@ifce.edu.br \\ Antonia de Abreu Sousa \\ ORCID: https://orcid.org/0000-0003-4970-4079 \\ Instituto Federal de Educação, Ciência e Tecnologia do Ceará, Brasil \\ E-mail: antonia@ifce.edu.br
}

\begin{abstract}
Resumo
O propósito central deste artigo é investigar quais os aspectos gerais estão relacionados à educação na (e para) a diversidade e como essas questões se relacionam e convergem com as postulações de uma Formação Humana Integral, tendo como contexto a Educação Profissional e Tecnológica (EPT). Ao demonstrarmos essas convergências propomo-nos a responder a seguinte indagação: Seria, de fato, o estudo da diversidade uma questão preponderante para o processo de formação humana em sua integralidade? Para tanto, foi realizada uma análise bibliográfica acerca da temática, com enfoque nos conceitos e contextualizações da diversidade, identidade e diferença, destacando como essas concepções estão permeadas pelas relações de poder existentes na sociedade e influem em suas construções sociais. Como direcionamento argumentativo, o artigo destaca alguns aspectos relacionados às diversidades de gênero, étnico-racial e sexual. Ao final da pesquisa foi possível reconhecer a real convergência entre o estudo histórico crítico da diversidade com as concepções da Formação Humana Integral, uma vez que a diversidade se encontra no escopo das relações sociais onde a vida é produzida, sendo que é justamente a análise crítica da totalidade das relações sociais um dos compromissos da Formação Humana Integral. Ademais, ao oferecer um estudo aprofundado das questões inerentes à diversidade, é possível compreender a gênese histórica de fenômenos como o racismo, o machismo e a homofobia e vislumbrar alternativas para a construção de uma sociedade mais justa e igualitária.
\end{abstract}

Palavras-chave: Diversidade; Formação humana integral; Identidade; Diferença.

\begin{abstract}
The main purpose of this article is to investigate which general aspects are related to education in (and for) diversity and how these issues relate to and converge with the postulations of an Integral Human Formation, in the context of Vocational and Technological Education (EPT). By demonstrating these convergences, we propose to answer the following question: Would the study of diversity be, in fact, a preponderant question for the process of human formation in its entirety? Therefore, a bibliographic analysis was carried out on the subject, focusing on the concepts and contextualization of diversity, identity and difference, highlighting how these conceptions are permeated by the existing power relations in society and influence its social constructions. As an argumentative direction, the article highlights some aspects related to gender, ethnic-racial and sexual diversities. At the end of the research, it was possible to recognize the real convergence between the critical historical study of diversity with the conceptions of Integral Human Formation, since diversity is in the scope of social relations where life is produced, and it is precisely the critical analysis of the totality of the social relations one of the commitments of the Integral Human Formation. Furthermore, by offering an in-depth study of the issues inherent to diversity, it is possible to understand the historical genesis of phenomena such as racism, machismo and homophobia and to envision alternatives for the construction of a more just and egalitarian society.
\end{abstract}

Keywords: Diversity; Integral human formation; Identity; Difference.

\section{Resumen}

El propósito principal de este artículo es indagar qué aspectos generales se relacionan con la educación en (y para) la diversidad y cómo estos temas se relacionan y convergen con los postulados de una Formación Humana Integral, en el contexto de la Educación Profesional y Tecnológica (EPT). . Demostrando estas convergencias, nos proponemos responder a la siguiente pregunta: ¿Sería el estudio de la diversidad, de hecho, una cuestión preponderante para el proceso de formación humana en su conjunto? Por lo tanto, se realizó un análisis bibliográfico sobre el tema, centrándose en los conceptos y la contextualización de la diversidad, la identidad y la diferencia, destacando cómo 
estas concepciones están permeadas por las relaciones de poder existentes en la sociedad e influyen en sus construcciones sociales. A modo de dirección argumentativa, el artículo destaca algunos aspectos relacionados con las diversidades de género, étnico-raciales y sexuales. Al final de la investigación se pudo reconocer la real convergencia entre el estudio histórico crítico de la diversidad con las concepciones de la Formación Humana Integral, ya que la diversidad está en el ámbito de las relaciones sociales donde se produce la vida, y es precisamente la análisis de la totalidad de las relaciones sociales uno de los compromisos de la Formación Humana Integral. Además, al ofrecer un estudio en profundidad de las cuestiones inherentes a la diversidad, es posible comprender la génesis histórica de fenómenos como el racismo, el machismo y la homofobia y vislumbrar alternativas para la construcción de una sociedad más justa e igualitaria.

Palabras clave: Diversidad; Formación humana integral; Identidad; Diferencia.

\section{Introdução}

A temática da diversidade tem se mostrado cada dia mais presente em nosso cotidiano. Discussões relacionadas à igualdade de gênero, racismo, políticas públicas afirmativas, desigualdade social, direitos de povos nativos, diversidade funcional, discriminação por orientação sexual e pluralidade cultural, por exemplo, são intrínsecas ao campo da diversidade e estão presentes, corriqueiramente, nas mídias sociais, em programas televisivos, nos debates políticos e demais espaços públicos.

Tamanha evidência em torno do universo temático da diversidade requer que adotemos cautela em nossas discussões, de modo que possamos realizar análises críticas entorno dos aspectos históricos e relações de poder que permeiam temas, como gênero, deficiência, sexualidade e identidades étnico-raciais, perpassando limites do senso comum e estabelecendo relações de causa e efeito que permitam melhor compreensão de como a diversidade influi na dinâmica das sociedades. Para tanto, de acordo com Rodrigues e Abramowicz (2013), o uso de maneira imprecisa ou indiscriminada do conceito de diversidade pode implicar no uso de estratégias políticas que levam ao apaziguamento de relações sociais muitas vezes conflituosas e até mesmo ao esvaziamento de significados, tratando a diversidade como mero sinônimo de diferença. Discutir a diversidade significa, além de tudo, discutir os fenômenos relacionados à pluralidade, à construção de identidades e à produção de diferenças.

Dentro do espectro de instituições sociais, a escola surge como uma das que possuem uma relação mais próxima do que possamos considerar como sendo o diverso, seja por sua função formativa, que lhe incumbe o papel de discutir as formações histórica e social dos povos, seja pelo fato de que é na escola que podemos observar refletida boa parte da diversidade que compõe a sociedade, facilmente identificada ao agregar, entre discentes, docentes, servidores e demais membros da comunidade escolar, inúmeras representações humanas, caracterizadas por diferenças de raça, gênero, corporalidades, orientações sexuais e classes sociais, dentre outros parâmetros.

Segundo Prado, Nogueira e Martins (2013), a escola é, além de tudo, uma instituição da esfera política, influindo nas formas de governança e organização da sociedade. Decorrente dessa concepção, segundo os autores, temos que a escola não deve ser reduzida aos seus aspectos técnico-educativos, tendo ela parte da responsabilidade por expandir o sentido público de uma sociedade, dos direitos e dos processos emancipatórios conflitivos. Deste modo, compreendemos que a escola deve assumir um papel mediador de conflitos e diferenças, mas não em sentido restrito, ou seja, não basta que a escola se preocupe em regular tais relações, mas compreendê-las e analisá-las (a partir de ações mais conscientes) em suas múltiplas dimensões, visando a superação de desigualdades historicamente construídas e, por conseguinte, alicerçar caminhos que levem à emancipação humana.

Ante o exposto, algumas indagações nos são suscitadas, tais como: Quais perspectivas educacionais se encaixariam nesse modelo de escola comprometida com uma formação emancipatória? De que maneira essas perspectivas poderiam se relacionar com o estudo crítico da diversidade e das diferenças, contribuindo para a superação das desigualdades presentes na nossa sociedade? 
Segundo Ciavatta (2005), a perspectiva da formação integral visa a superação da divisão do homem ocasionada por meio da divisão social do trabalho, tornando-o íntegro, completo. $\mathrm{O}$ ideal de formação humana, por sua vez, perpassa a apropriação dos conhecimentos necessários para que possamos fazer uma leitura completa do mundo, a compreender as relações sociais que estão subjacentes a todos os fenômenos e permitir a plena integração dos cidadãos à sociedade. É a partir dessa compreensão dos fenômenos e de suas relações subjacentes que é possível o alcance da emancipação humana, visto que, segundo Ciavatta (2005, p. 2), "a emancipação humana se faz na totalidade das relações sociais onde a vida é produzida".

O horizonte da Formação Humana Integral (FMI), que em seu cerne vislumbra a compreensão e a análise crítica dos fenômenos que estão imersos na sociedade em sua totalidade, tem um potencial extremamente valoroso para a discussão da temática da diversidade ao permitir que durante a formação educacional dos indivíduos, de modo contextualizado e interdisciplinar, estes possam questionar, compreender e ressignificar contextos e comportamentos que, de forma regular e sistemática, promovam a reprodução de desigualdades. Discutir a temática da diversidade a partir da perspectiva da FMI é justificada, portanto, pela necessidade de se apresentar outras perspectivas de análise acerca da produção de diferenças e identidades, colaborando para um aprofundamento crítico dos fenômenos sociais e para a identificação de possibilidades de atuação e intervenção no combate a fenômenos, como racismo, machismo, homofobia e xenofobia, dentre outros, que são permeados por relações de poder e construídos historicamente a partir de relações de exploração e dominação. A partir destas considerações podemos caracterizar a problemática central desta pesquisa como sendo a compreensão da relação diversidade e educação sob a perspectiva de FMI e as suas possíveis convergências no propósito de contribuir para a emancipação humana e construção de uma sociedade mais justa.

\section{Metodologia}

A pesquisa aqui apresentada encontra-se na categoria das pesquisas qualitativas, uma vez que se propõe a explorar determinado fenômeno a partir da coleta de dados em diversas instâncias, buscando sua compreensão a partir de concepções filosóficas, análise do contexto, construção histórica e visão integrada dos elementos que constituem o fenômeno investigado (Creswell, 2010).

Para a estruturação do trabalho foi realizada, inicialmente, uma revisão bibliográfica sobre a temática da diversidade, focando nas publicações de artigos e livros que abordem essa temática sob a ótica educacional e que trabalhem em cima de questões como a identidade e a diferença, visto a contemporaneidade e problemática dessas questões.

Como forma de direcionamento dos estudos, a pesquisa recorreu aos estudos de gênero, das diversidades sexual e étnico-racial, além de estudos relacionados ao multiculturalismo. A partir desses estudos foi possível a identificação e caracterização de alguns dos principais grupos sociais subalternizados e os fenômenos característicos dessa subalternização como, por exemplo, o machismo, a homofobia, a lesbofobia, a transfobia e o racismo.

Identificados os grupos e os fenômenos anteriormente descritos, foi possível reconhecer como se deram, historicamente, as relações de poder e dominação que vigem na sociedade contemporânea e como se moldaram ao modelo econômico neoliberal visando a manutenção de suas bases hegemônicas. Em paralelo à investigação sobre a diversidade, foram realizadas leituras e apontamentos acerca da FMI, identificando conceitos-chave e estabelecendo as devidas correlações e convergências com a diversidade na (e para) educação.

Por fim, destacamos o cunho reivindicatório e participatório da pesquisa, tendo em vista que partindo das contribuições e dos escritos teórico-científicos já publicados é possível, a partir dessa concepção filosófica, oportunizar aos grupos socialmente marginalizados e privados de privilégios a possibilidade de exporem suas necessidades, bem como a necessidade de mudanças na sociedade a partir de novas perspectivas teóricas (Creswell, 2010). 


\section{Resultados e Discussão}

Ao propormos a discussão acerca da temática da diversidade tivemos como propósito identificar os principais conceitos que são inerentes a esse tema, bem como as conciliações e disputas decorrentes dos múltiplos atravessamentos que estão presentes em categorias como sexo, gênero e raça. Com base no referencial teórico apresentado, identificamos que os grupos historicamente subalternizados estão em constante luta por reconhecimento e pela garantia de seus direitos.

A perpetuação das desigualdades historicamente construídas engloba diversas instâncias sociais. A educação e a escola, por sua vez, podem acabar atuando como reprodutoras dessas desigualdades, principalmente quando não estiverem comprometidas com um modelo educacional que preze pela formação humana em suas múltiplas dimensões e que não propiciem a compreensão e problematização dos fenômenos geradores da realidade social.

Tendo como premissa buscar concepções filosóficas e ideológicas comprometidas com a ruptura do modelo educacional reprodutivista presente na sociedade capitalista e que possa englobar os estudos da diversidade em seus aspectos históricos críticos visando a construção de uma sociedade menos desigual, vislumbramos na FMI um modelo compatível e convergente com esse propósito.

A partir das ideias inerentes à concepção da FMI é possível pensar formas de romper ou contornar a dualidade presente na educação brasileira que é pautada na oferta de formações educacionais distintas para os diversos grupos sociais, de modo a privilegiar os que pertencem às classes dominantes com uma formação ampla, em contraposição à educação destinada aos grupos subalternizados, de caráter restrito e tecnicista. Uma escola comprometida com a FMI pode contribuir, portanto, para dar voz e espaço a todos os diversos grupos sociais, instruindo-os para além do senso comum e desvinculando-se de padrões e comportamentos geradores de desigualdades.

\section{A Diversidade e Alguns Pormenores}

A diversidade está relacionada ao conjunto da variabilidade humana, perpassando questões socioculturais, étnicoraciais, de gênero, sexuais, dentre outras. Engloba aquilo que difere os indivíduos e pluraliza o contexto social. Corrobora com essa visão a seguinte definição:

O substantivo feminino diversidade pode significar variedade, diferença e multiplicidade. A diferença é a qualidade do que é diferente, o que distingue uma coisa da outra, a falta de igualdade ou de semelhança. A variedade diz respeito a qualidade, atributo ou atestado de algo que possui diferentes formas ou tipos que se diversificam dentro de uma classe. A multiplicidade diz respeito a grande número ou variedade de algo. (Silvério, 2005, p. 87).

Sob a perspectiva dos conceitos em epígrafe, estudar a diversidade no âmbito social significa recorrer aos estudos de gênero, das diversidades sexual e étnico-racial, bem como do multiculturalismo, uma vez que estes campos de estudo fornecem subsídios que permitem realizar uma análise histórico-crítica dos fatores e fenômenos correlacionados à temática da diversidade, evidenciando e afirmando as diferenças como elementos constituintes da sociedade.

A afirmação da diferença, como sugerido no parágrafo anterior, perpassa uma análise da correlação entre identidade e diferença, visto que esses conceitos se desnudam, ou seja, se evidenciam quando postos em uma análise dialética.

Em que consiste, então, nossa identidade? Podemos dizer, por exemplo: "somos mulheres, somos homens, somos mães, somos pais". A identidade expressa, nesse caso, "aquilo que somos". Contudo, aprendemos o que somos em meio às relações que estabelecemos, tanto com os nossos "semelhantes" (somos, todos nós, brasileiros) quanto com os que diferem de nós (somos meninos, por não sermos meninas). Aprendemos também o que somos em meio aos significados atribuídos, pelos outros, "àquilo que somos" (por sermos meninos, não devemos chorar na frente dos outros; por sermos meninas, podemos brincar com bonecas). (Moreira \& Câmara, 2008, p. 41). 
As considerações dos autores citados demonstram não só que as identidades são construídas com base no contexto social dos indivíduos, mas a percepção da diferença se dá de maneira altera, naquilo que não somos. "As afirmações sobre identidade, assim, envolvem afirmações, não explicitadas, sobre outras identidades diferentes da nossa.” (Moreira \& Câmara, 2008, p. 43).

Se a diversidade é inerente à sociedade e se a formação das identidades está no reconhecimento daquilo que lhe é diferente e, certamente, cada um de nós possui uma identidade, qual a necessidade factual do estudo da diversidade? Quais as problemáticas envoltas nesta temática que lhe fornecem relevância para a pesquisa científica? As respostas para essas indagações incidem no fato de que, no seio da sociedade, as interações e relações sociais não se dão de maneira harmônica.

De início é importante destacar que a formação das identidades é diretamente afetada pelas transformações nos contextos históricos e sociais. Vejamos:

As identidades e as lealdades políticas também têm sofrido mudanças: lealdades tradicionais, baseadas na classe social, cedem lugar à concepção de escolha de 'estilos de vida' e à emergência da 'política de identidade'. A etnia e a 'raça', o gênero e a sexualidade, a idade, a incapacidade física, a justiça social e as preocupações ecológicas produzem novas formas de identificação. As relações familiares também têm mudado, especialmente com o impacto das mudanças na estrutura do emprego. Tem havido mudanças também nas práticas de trabalho e na produção e consumo de bens e serviços (Woodward, 2014, p. 32).

Segundo Abramowicz, Rodrigues e Cruz (2011), compreender a diversidade e as diferenças significa, acima de tudo, perceber que esses conceitos estão cercados de disputas sócio-políticas e relações de poder historicamente constituídas. Analisar a diversidade de forma universalista acaba por invisibilizar as diferenças e as disputas sociais e políticas onde estão imersas e corroborar com a perpetuação das desigualdades. Não basta reconhecer o diferente, é necessário incitá-lo, criá-lo e produzi-lo.

\subsection{As diversidades}

Reconhecer o diverso (e as diferenças) só é possível traçando um distanciamento daquilo que é tido como o padrão normativo da sociedade. Mas qual padrão seria esse? Segundo Scott, Lewis e Quadros (2009, p.15), atualmente “Assiste-se o apogeu de uma idealização homogeneizadora da norma do homem branco de classe média heterossexual, rejeitando a veiculação de ideias que desautorizam o exercício pleno de outras formas de constituições identitárias". Temos então um ponto de partida: o homem (componente de gênero, masculino), classe média (componente econômico e social), o heterossexual (componente sexual) e o branco (componente étnico-racial). Textos de Louro (2014), Reis (2015) e Gomes (2008), em suas respectivas áreas de pesquisa, apresentam posicionamentos convergentes sobre hegemonia desses componentes.

Ainda segundo Scott et al. (2009, p.15): “As questões de desigualdades de gênero, sexualidade, 'raça' e classe (e a intersecção destas várias categorias multiplicando e complexificando as relações de poder) têm se constituído como um dos principais campos de força na demarcação da noção de um indivíduo normatizado.”

Durante a elaboração da pesquisa bibliográfica foi possível identificar que as temáticas relacionadas a gênero, sexo, etnia e raça são abordadas, em grande maioria, de forma isolada ou com alguns recortes transversais. Isso deve-se ao fato desses campos possuírem especificidades que, para uma compreensão a fundo, requerem uma análise direcionada. Contudo, a despeito dessas inúmeras especificidades, é possível estabelecer aspectos em comum e intersecções entre esses segmentos de estudo. Dessa forma, apresentaremos, a seguir, alguns elementos e problemáticas específicas das diversidades de gênero, sexual e étnico-racial e, posteriormente, alguns pontos de interseção entre elas. 


\subsubsection{Diversidade de gênero}

Segundo Louro (2014) a ascensão do termo gênero ocorre quando as feministas anglo-saxãs utilizam o termo (gender) de forma contraposta ao sexo (sex), ou seja, como forma de transpor os limites e determinismos relacionados ao sexo biológico. Há ainda, segundo a autora, a incorporação do social como fator fundamental para a definição do gênero, isto é, "o conceito pretende se referir ao modo como as características sexuais são compreendidas e representadas ou, então, como são "trazidas para a prática social e tornadas parte do processo histórico." (Louro, 2014, p. 25).

Se o gênero são os significados culturais assumidos pelo corpo sexuado, não se pode dizer que ele decorra, de um sexo desta ou daquela maneira. Levada ao seu limite lógico, a distinção sexo/gênero sugere uma descontinuidade radical entre corpos sexuados e gêneros culturalmente construídos. Supondo por um momento a estabilidade do sexo binário, não decorre daí que a construção de "homens" se aplique exclusivamente a corpos masculinos, e que o termo "mulheres" interprete somente corpos femininos. Além disso, mesmo que os sexos pareçam não problematicamente binários em sua morfologia e constituição (ao que será questionado), não há razão para supor que os gêneros também devam permanecer em número de dois. A hipótese de um sistema binário dos gêneros encerra implicitamente a crença numa relação mimética entre gênero e sexo, na qual o gênero reflete o sexo ou é por ele restrito. Quando o status construído do gênero é teorizado como radicalmente independente do sexo, o próprio gênero se torna um artifício flutuante como a consequência de que homem e masculino podem, com igual facilidade, significar tanto um corpo feminino como um masculino, e mulher e feminino, tanto um corpo masculino como um feminino. (Butler, 2021, p. 26).

É através dessa visão de que é no âmbito das relações sociais que se constroem os gêneros que se busca suplantar os determinismos e generalizações quanto ao que pertence ao homem e ao que pertence a mulher. Segundo Reis (2015), historicamente há uma tendência de submissão da mulher perante o homem, visto que a este são atribuídas características tidas como superiores, tanto físicas quanto psicológicas. Ao homem a racionalidade (qualidade superior), à mulher a passionalidade e a passividade (qualidades tidas como inferiores).

A valorização e crença da superioridade das "características masculinas" são o cerne do que conhecemos como machismo. A aversão e o desprezo aos elementos femininos e à mulher nutrem o que entendemos por misoginia. $\mathrm{O}$ machismo e a misoginia têm provocado, ao longo das gerações, o distanciamento das mulheres dos espaços de fala e participação social, além das recorrentes manifestações de controle dos seus corpos, o que Michel Foucault (2008) veio a denominar de biopoder, “ou seja, o poder de controlar as populações, de controlar o 'corpo-espécie'.” (Louro, 2014, p. 45).

Os movimentos que se propõem a discutir e ressignificar a formação das identidades por meio do recorte de gênero, destacando o caráter social, histórico e cultural que marcam a formação das identidades de gênero em contraposição à lógica determinista utilizada pelos critérios biológicos atribuídos ao sexo, enfrentam fortes oposições vindas de movimentos reacionários que se valem, inúmeras vezes, de concepções deturpadas de conceitos como "ideologia de gênero" e "marxismo cultural" para impedir o avanço de pautas que culminem em direitos e liberdades sobre os corpos e as práticas sexuais.

O espantalho da "ideologia de gênero" tornou-se, no Brasil, o ingrediente principal do "marxismo cultural", outra importação do radicalismo de direita anglófono. Nas palavras de Mirrless, o "marxismo cultural" é um dispositivo político de produção de "ódio interseccional" dentro do discurso da Alt-Right (a nova extrema direita). Ele constrói uma visão de nação que é patriarcal, branca e supremacista cristã, "em resposta à desestabilização desta ordem pela contínua busca de justiça social e mudanças societais mais amplas ligadas às condições do capitalismo multinacional e do neoliberalismo progressista." (Miguel, 2020, pp. 4-5).

A consequência natural do avanço das pautas reacionárias que visam minar quaisquer avanços que almejam a igualdade de gêneros é a manutenção dos privilégios das categorias hegemônicas da sociedade, sendo essa marcada por seu caráter patriarcal, branco e heterossexual. Para Cunha (2020), a manutenção dos padrões de gênero atrelados ao determinismo 
biológico termina por reforçar a desigualdade social a partir do patriarcado, impõe modos de condutas distintos para homens e mulheres, favorece a ocorrência de manifestações de violência, assédio e desigualdade salarial, além de outras demonstrações de desigualdade inerentes a sociedades com relações de poder assimétricas entre os gêneros.

\subsubsection{Diversidade sexual}

Se recorrermos aos estudos de Reis (2015) iremos identificar que a crença da supremacia do masculino em relação ao feminino agride não somente as mulheres, mas também os homens que, eventualmente, apresentem características que não sejam condizentes com sua condição de "sujeito homem". Ao pesquisar a questão sexual nas civilizações antigas, mais especificamente na Grécia de Platão e Aristóteles, percebemos que a valorização da racionalidade acaba por sobrepujar as questões emocionais e sexuais. "Concretizou-se nesta civilização da antiguidade um processo de estigmatização do ato sexual e de inferiorização da mulher, que foi absorvido pelas culturas ocidentais até a contemporaneidade" (Reis, 2015, p. 38).

Essa concepção filosófica grega em relação ao sexo e, posteriormente, absorvida pelo cristianismo tem como um de seus sustentáculos a abdicação do prazer sexual. O sexo deve, portanto, assumir um único papel: o reprodutivo. Daí temos que:

[...] numa sociedade que considera o sexo apenas sob o prisma da reprodução da espécie, ou como função biológica, serão reprimidas todas as atividades sexuais em que o sexo genital for praticado sem cumprir aquela função: masturbação ou onanismo, homossexualismo masculino ou feminino (ou sodomia), sexo oral (felação, cunilíngua), sexo anal, coito interrompido, polução sem penetração (voyeurismo). (Chauí, 1991 como citado em Reis, 2015, p. 41).

Com base no fragmento citado, depreendemos que as manifestações sexuais que se distanciem do padrão heterossexual, que não se atenham à função reprodutiva ou que subvertam os arquétipos masculino e feminino são um afronte aos dogmas religiosos e até mesmo àqueles tido como "naturais". As orientações sexuais e identidades de gêneros são, nesse ponto, alvo de forte controle social, aqueles que divergem do padrão heteronormativo enfrentam inúmeras formas de discriminação, segregação e violência.

Percebemos, portanto, que o controle da sexualidade é mais uma manifestação de como o sexo e o poder estão imbricados em uma relação coextensiva, de modo que os padrões de sexualidade vigentes em uma determinada época nada mais são que o reflexo do poder que atua nessa área. Desse modo, todas as manifestações sexuais que se distanciam do modelo tido como aceitável passam a assumir um caráter subversivo.

O poder, ao invés da lei, abrange tanto as funções ou relações diferenciais jurídicas (proibitivas e reguladoras) como as produtivas (inintencionalmente generativas). Consequentemente, a sexualidade que emerge na matriz das relações de poder não é uma simples duplicação ou cópia da lei ela mesma, uma repetição uniforme de uma economia masculinista da identidade. As produções se desviam de seus propósitos originais e mobilizam inadvertidamente possibilidades de "sujeitos" que não apenas ultrapassam os limites da inteligibilidade cultural como efetivamente expandem as fronteiras do que é de fato culturalmente inteligível. (Butler, 2021, p. 63).

Com finalidade sintética, englobaremos a discriminação de gays, lésbicas, bissexuais, transexuais, etc sob a perspectiva da homofobia, visto que esse conceito, segundo Herek (1991) e UNAIDS (2007) como citado em Reis (2015, p. 29) refere-se "[...] à hostilidade, à intolerância e ao desprezo a todas as orientações e identidades sexuais diferentes ou divergentes da heterossexual." Destacamos, contudo, que as categorias citadas possuem elementos específicos em suas problemáticas. Ainda sobre a homofobia, podemos destacar que se trata de um fenômeno complexo e variado. Podemos entrevê-la em piadas vulgares que ridicularizam o indivíduo efeminado; no entanto, ela pode revestir-se também de formas mais brutais, chegando inclusive à exterminação, como foi o caso na Alemanha nazista.” (Borrillo, 2001, como citado em Reis, 2015, p. 30). 
Facchini (2010) e Facchini, Carmo e Lima (2020) pontuam pertinentemente as disputas e transformações em torno da pauta dos direitos homossexuais no Brasil. Em seus trabalhos, esses autores evidenciam, por exemplo, os impactos que a epidemia de AIDS provocou nos movimentos reivindicatórios, de modo que pautas relacionadas à liberdade sexual tiveram que dar espaço à luta contra a epidemia que trazia, em sua gênese, uma forte estigmatização contra os homossexuais, sendo chamada de "peste gay". Foi a partir das reivindicações dos grupos de luta pelos direitos da população sexual que conquistas como definição da categoria "orientação sexual”, que se distanciava das perspectivas essencialistas quanto à condição homossexual, e a exclusão da homossexualidade como condição patológica.

\subsubsection{Diversidade étnico-racial}

A diversidade étnico-racial e suas problemáticas correlatas estão permeadas por relações históricas de dominação. Segundo Hall (2003), as configurações multiétnicas e multiculturais não são fenômenos recentes e podem ser observados nos distintos impérios existentes durante a Idade Antiga. Para o autor, as tradições colonizadoras e de dominação desses impérios contribuíram para que viessem a se tornar multiculturais. Contudo, o fim do colonialismo, ao menos em sua forma primitiva, não foi suficiente para que os povos subalternizados pudessem se desenvolver plenamente e superar os problemas causados pela dominação. Podemos identificar que

[...] o "pós-colonial” não sinaliza uma simples sucessão cronológica do tipo antes/depois. O movimento que vai da colonização aos tempos pós-coloniais não implica que os problemas do colonialismo foram resolvidos ou sucedidos por uma época livre de conflitos. Ao contrário, o "pós-colonial" marca a passagem de uma configuração ou conjuntura histórica de poder para outra. (Hall, 1996a). Problemas de dependência, subdesenvolvimento e marginalização, típicos do "alto" período colonial, persistem no pós-colonial. Contudo, essas relações estão resumidas em uma nova configuração. No passado, eram articuladas como relações desiguais de poder e exploração entre as sociedades colonizadoras e as colonizadas. Atualmente, essas relações são deslocadas e reencenadas como lutas entre forças sociais nativas como contradições internas e fontes de desestabilização no interior da sociedade descolonizada, ou entre ela e o sistema global como um todo. (Hall, 2003, p. 56).

A partir das proposições de Stuart Hall é possível direcionarmos a análise da relação colonizador/colonizado e sua reconfiguração após seu fim, ao menos sem sua forma institucional-legal, à questão da escravidão. No caso brasileiro, por exemplo, a abolição da escravatura, ocorrida em 1888, não se deu acompanhada de qualquer medida de reparação dos danos causados pela escravidão à população negra, fazendo com que essa permanecesse em um sistema de exploração, pobreza, marginalização e estigmatização social. Muitas destas questões perduram até hoje sob a forma de um racismo estrutural.

Nessa perspectiva, a prevalência das características "superiores" do colonizador ou, contemporaneamente, dos "hierarquicamente superiores" (que ocupam as posições privilegiadas no jogo das relações de poder) são absorvidas, inclusive, pelos subalternizados que as idealizam e, por consequência, as legitimam como superiores e como padrão a ser seguido. A "branquitude" pode ser vista como manifestação desse fenômeno.

Esta refere-se, segundo Bento (2002), aos traços da identidade racial do branco brasileiro, uma dimensão subjetiva formulada no contexto das relações de poder e raciais do nosso país. De acordo com a autora, a "branquitude" é a produção de uma identidade racial que toma o branco como padrão de referência de toda uma espécie. Nesse processo, constrói-se uma apropriação simbólica formulada pelas elites que fortalece a auto-estima e o autoconceito do grupo branco em detrimento dos demais. Essa apropriação acaba legitimando a supremacia econômica, política e social do grupo visto como branco no Brasil. Em contrapartida, constrói-se um imaginário extremamente negativo sobre o negro, que solapa a identidade racial, danifica sua auto-estima, culpa-o pela discriminação que sofre e ainda justifica as desigualdades raciais. (Gomes, 2008, p. 73). 
Essa "dinâmica da discriminação" alimenta toda uma cadeia de desigualdades e nos leva ao mesmo entendimento de Sousa (2015, p. 107), quando nos diz: “A discriminação racial divide e exclui os indivíduos, condicionando categorias e hierarquias fundadas em concepções preconceituosas que contribuem para a construção de uma estrutura social profundamente desigual."

Dentre as estratégias utilizadas para dirimir os impactos causados pela discriminação étnico-racial historicamente constituída no Brasil, as políticas de ações afirmativas têm galgado importantes espaços e dado contribuições para a inclusão de grupos étnico-raciais historicamente privados do acesso a direitos básicos como, por exemplo, o acesso à educação (Santos, 2013; Piovesan, 2008). Em linhas gerais, as ações afirmativas podem ser definidas como:

[...] todo programa, público ou privado, que tem por objetivo conferir recursos ou direitos especiais para membros de um grupo social desfavorecido, com vistas a um bem coletivo. Etnia, raça, classe, ocupação, gênero, religião e castas são as categorias mais comuns em tais políticas. Os recursos e oportunidades distribuídos pela ação afirmativa incluem participação política, acesso à educação, admissão em instituições de ensino superior, serviços de saúde, emprego, oportunidades de negócios, bens materiais, redes de proteção social e reconhecimento cultural e histórico. (Feres Júnior et al., 2018, p. 13).

As cotas raciais, uma das principais políticas de ação afirmativa existentes no país, juntamente com outras políticas voltadas à permanência e ao êxito dos alunos, aos poucos tem começando a subverter uma realidade construída historicamente que, de maneira estrutural, inibia o acesso da população negra ao nível superior. Conforme apontado pelo Instituto Brasileiro de Geografia e Estatística (IBGE) (2019), com dados obtidos na Pesquisa Nacional por Amostra de Domicílios Contínua 2018, a população preta ou parda presente na rede pública de ensino superior atingiu um percentual de 50,3\%, passando a compor a maioria dos estudantes desse segmento pela primeira vez.

\subsubsection{Pontos de interseção na diversidade}

Os campos de estudo na área da diversidade não necessariamente precisam traçar caminhos separados. Dentre os inúmeros segmentos e suas especificidades, aqui destacados nos estudos das diversidades de gênero, sexual e étnico-racial, há uma série de interconexões e interseções, sejam elas de ordem histórica, política, cultural ou social. Essas ligações contribuem para uma maior compreensão da complexidade que envolve o tecido social e para a proposição de intervenções sociais tendo como objetivo final comum a todos a constituição de uma sociedade mais justa, democrática e menos desigual.

Seus objetos de análise são aproximados, as identidades com que lidam se articulam, se misturam e se complexificam. Além disso, a forma como se aproximam dos objetos é semelhante: são campos de estudos marcadamente engajados, dirigidos não apenas para a análise, mas para a intervenção social. São ainda campos científicos "abertos", pouco ortodoxos, marcados pelo debate e pela diversidade analítica. Estudos das culturas juvenis, da cultura operária, da mídia, das identidades nacionais, étnicas e sexuais têm "tudo a ver" com gênero, obviamente. As alianças são assim produtivas em todas as direções. (Louro, 2014, p. 161).

O posicionamento da autora, posto ao considerar a importância de oxigenar o debate feminista agregando elementos de outros campos de estudo, é fundamentado na ideia da multipluralidade de identidades, onde os indivíduos podem (e são) mais de uma "coisa". Convergente com esse pensamento, temos as seguintes considerações de Butler (2021, p. 21):

Se alguém é uma mulher, isso certamente não é tudo o que esse alguém é; o termo não logra ser exaustivo, não porque os traços predefinidos de gênero da pessoa transcendam a parafernália específica de seu gênero, mas porque o gênero nem sempre se constitui de maneira coerente ou consistente nos diferentes contextos históricos, e porque o gênero estabelece interseções com modalidades raciais, classistas, étnicas, sexuais e regionais de identidades discursivamente 
constituídas. Resulta que se tornou impossível separar a noção de gênero das interseções políticas e culturais em que invariavelmente ela é produzida e mantida.

Essa reflexão é importante, pois é necessário que seja desenvolvida uma consciência crítica ampla, complexa e analítica das relações de poder onde todos estão inseridos. Ao pensarmos a interseccionalidade e a transversalidade presente entre as diversas categorias sociais estamos pensando em espaços de conciliação e de disputa que, caso observados sob um olhar extremamente enviesado pode resultar em ações contraditórias entre os subalternizados como, por exemplo, o negro que adota comportamentos machistas ou a mulher com posturas homofóbicas, além do não reconhecimento das especificidades que as categorias eventualmente possuam. Nestes casos, os indivíduos acabam ocupando posições de opressor e oprimido a depender da dinâmica social sob análise.

É perceptível também, e isso corrobora com esse entrelaçamento das relações de poder vivenciadas pelos que são subalternizados, que, nos dizeres de Michel Foucault (2019, p. 148) "o poder se situa e é exercido no nível da vida, da espécie, da raça e dos fenômenos maciços da população". Outra consideração perspicaz de Foucault ocorre quando ele identifica as relações entre a sexualidade, por meio do que veio a chamar de dispositivo da sexualidade, e o racismo, em torno de uma dinâmica de controle e manutenção do poder político.

O racismo se forma nesse ponto (racismo em sua forma moderada, estatal, biologizante): toda uma política do povoamento, da família, do casamento, da educação, da hierarquização social, da propriedade, e uma longa série de intervenções permanentes no nível do corpo, das condutas, da saúde, da vida cotidiana, recebera, então cor e justificação em função da preocupação mítica de proteger a pureza do sangue e fazer triunfar a raça. (Foucault, 2019, p. 162).

Em outros termos, o que Foucault nos diz é que para que haja a devida manutenção das relações hegemônicas vigentes na sociedade, e aqui tratamos da sociedade capitalista moderna, é posta uma nova configuração de racismo, que segmenta, estratifica, age sobre os corpos e os comportamentos, de modo a consolidar os padrões de dominação e dispersar eventuais ameaças a sua continuidade. Ainda segundo esse autor, é nesse contexto que há a ascensão do regime nazista e sua teoria eugenista.

Para encerrar essa breve passagem pelas intersecções entre os campos da diversidade, e logicamente sem a intenção de esvaziar o tema, é proeminente que teçamos alguns comentários acerca de como a diversidade e as diferenças são abarcadas no contexto do neoliberalismo.

Ao que parece temos a diversidade, esvaziada da diferença, e o campo da diferença esvaziada pelo campo da diversidade. De um lado a tolerância, que é um campo amplo, inclusive em voga no neoliberalismo de aceitação das diferenças e o capital operando na produção de mercadorias geradas pelas diferenças e, de outro lado, a ideia de que nada tem que ser tolerado, já que não é disto que se trata. O neoliberalismo se aproveita da palavra de ordem pela diferença que significa a possibilidade de ampliação do mercado. Quanto mais diferenças, melhor. (Abramowicz et al., 2011, p. 93).

Aqui retornamos ao ponto já citado anteriormente sobre como a abordagem da diversidade e das diferenças pode levar ao esvaziamento de seus significados se não houver um cuidado em caracterizar como essas diferenças são produzidas, senão por meio de relações de dominação e exploração. Desse modo, a diversidade e as diferenças são colocadas em uma relação produto/consumidor pelo sistema neoliberal que que usa essas palavras "como estratégia de ampliação das fronteiras do capital, pela maneira com que comercializa territórios de existência, formas de vida, a partir de uma maquinaria de produção de subjetividades" (Abramowicz et al., 2011, p. 91). 


\section{A Formação Humana Integral}

O modelo de produção capitalista, potencializado pelo modelo neoliberal, traz consigo inúmeras questões contraditórias e dualísticas. Dentre essas dualidades, chamaremos a atenção para uma em especial: a dualidade na formação dos indivíduos. Essa dualidade tem como característica básica a existência de dois polos teleologicamente distintos: um tipo de formação destinada às elites dominantes e outro tipo de formação destinada aos estratos populares fadado ao papel de mão de obra na sociedade capitalista. A formação em questão é a de cunho educacional, sendo que para as classes dominantes é destinada uma formação completa, visando a formação de futuros dirigentes, portanto, uma formação para o trabalho intelectual; para as classes populares é reservada uma formação tecnicista, destinada a formação de mão de obra, portanto, uma formação para o trabalho manual. Aqui identificamos como é inerente ao capitalismo reproduzir as estruturas e instâncias que o reafirmem e garantam a sua perpetuação, uma vez que "sabemos que a dualidade educacional é uma manifestação específica da dualidade social inerente ao modo de produção capitalista" (Ramos, 2008, p. 1).

A superação dessa dualidade se dá, por exemplo, a partir da ascensão de uma nova concepção de escola e educação que vise superar as desigualdades e educar para a emancipação humana. Esse é o ideal da escola unitária que em seu cerne

[...] expressa o princípio da educação como direito de todos. Uma educação de qualidade, uma educação que possibilite a apropriação dos conhecimentos construídos até então pela humanidade, o acesso à cultura, etc. Não uma educação só para o trabalho manual e para os segmentos menos favorecidos, ao lado de uma educação de qualidade e intelectual para o outro grupo. Uma educação unitária pressupõe que todos tenham acesso aos conhecimentos, à cultura e às mediações necessárias para trabalhar e para produzir a existência e a riqueza social. (Ramos, 2008, p. 2).

Essa concepção de escola unitária visa a ruptura do paradigma educacional no modelo capitalista e, com isso, a sua substituição por um novo modelo que forme a todos os cidadãos, independentemente de suas classes sociais, na totalidade dos aspectos científicos, laborais, culturais, sociais, etc. uma vez que, conforme Ciavatta (2005, p.2) “a emancipação humana se faz na totalidade das relações sociais onde a vida é produzida".

Podemos dizer, portanto, que a escola unitária só é viável desde que adote um modelo de integração entre os universos do trabalho, da ciência e da cultura.

A formação integrada sugere tornar íntegro, inteiro, o ser humano dividido pela divisão social do trabalho entre a ação de executar e a ação de pensar, dirigir ou planejar. Trata-se de superar a redução da preparação para o trabalho ao seu aspecto operacional, simplificado, escoimado dos conhecimentos que estão na sua gênese científico-tecnológica e na sua apropriação histórico-social. Como formação humana, o que se busca é garantir ao adolescente, ao jovem e ao adulto trabalhador o direito a uma formação completa para a leitura do mundo e para a atuação como cidadão pertencente a um país, integrado dignamente à sua sociedade política. Formação que, neste sentido, supõe a compreensão das relações sociais subjacentes a todos os fenômenos. (Ciavatta, 2005, p. 3).

A gênese conceitual de uma formação humana integrada pode ser observada a partir do século XIX, sendo nos escritos de Marx, Engels e Gramsci que essa visão toma uma forma mais concreta em conceitos como politecnia, formação politécnica e formação omnilateral. É um ponto de convergência entre esses autores a ideia de que esse tipo de formação se refere "a uma possibilidade futura a ser materializada em uma sociedade na qual a classe trabalhadora tenha conquistado o poder político.” (Moura, 2013, p. 707).

Assim, quando discutem a educação do tempo em que viveram, ou seja, em uma sociedade capitalista, esses autores admitem a possibilidade da profissionalização quando associada à educação intelectual, física e tecnológica, compreendendo-a como o germe da educação do futuro (Marx, 1996 como citado em Moura, 2013, p. 707). 
Essa perspectiva educacional futura é observada em Gramsci quando, "[...] segundo o autor, as condições materiais concretas da sociedade de sua época impediam a plena materialização da politecnia" (Moura, 2013, p. 712). Em relação ao termo politecnia é importante esclarecer que não significa o que à primeira vista pode sugerir. "Politecnia significa uma educação que possibilita a compreensão dos princípios científico-tecnológicos e históricos da produção moderna, de modo a orientar os estudantes à realização de múltiplas escolhas" (Ramos, 2008, p.3).

É sabido que os pensamentos de origem marxista, bem como daqueles diretamente influenciados por suas ideias como é o caso de Gramsci, são concebidos tendo como foco a discussão acerca da dinâmica da sociedade capitalista caracterizada pela dominação de classes e do seu aspecto materialista histórico. Tal centralidade é ainda presente entre muitos teóricos de abordagem crítica, contudo é perceptível que mesmo entre esses teóricos há um movimento de renovação caracterizado por concepções pluralistas, que contemplam, por exemplo, o:

capitalismo desenvolvido e luta de classes, capitalismo de Estado e reificação, Estado social e as ambiguidades da política, Estado de direito e a democratização de suas instituições, novos movimentos sociais e as lutas por reconhecimento, etc. (Nobre, 2008). Os diagnósticos mostram que dominação e emancipação são constituídas por fatores múltiplos (economia, cultura, política), relacionam-se de modo variado com os portadores da emancipação (proletariado, estudantes, negros, mulheres, minorias multiculturais) e precisam ser investigadas com base em um arranjo interdisciplinar das pesquisas sociais (sociologia, economia, filosofia, direito, psicanálise). (Melo, 2017, p. 168).

Mesmo passados anos após as proposições de Marx, Engels e Gramsci é fácil de identificar que o futuro ainda não chegou! O futuro a que nos referimos é aquele onde a coletividade tenha conseguido transpor as barreiras impostas pelo capital e que impedem homens e mulheres de se emanciparem e se formarem em sua integralidade. $\mathrm{O}$ futuro presente, contudo, nos trouxe algumas ressignificações, quando não polissemias. A FMI não ficou alheia a esse processo. Segundo Ramos (2008) podemos estabelecer três sentidos para a integração: a formação omnilateral, a indissociabilidade entre educação profissional e educação básica e a integração de conhecimentos gerais e específicos como totalidade.

O primeiro sentido, segundo a autora, fundamenta-se na formação omnilateral aplicada ao ensino médio, etapa final da educação básica, visando a superação da vinculação e do compromisso histórico dessa etapa do ensino com o mercado de trabalho e inserindo as perspectivas de emancipação humana nas práticas formativas dos educandos. Nesse sentido, o trabalho é encarado como princípio educativo, ou seja, a partir da formação de uma consciência crítica sobre a produção humana onde é através do trabalho que o homem constrói sua própria existência (sentido ontológico), contudo reconhecendo que no sistema capitalista há um direcionamento reducionista ao caráter econômico e produtivo do trabalho (sentido histórico). A essa concepção de trabalho também devem ser incluídos os princípios da ciência enquanto conjunto dos conhecimentos produzidos, sistematizados e legitimados socialmente pela humanidade e da cultura que relaciona os valores e normas que levam à estruturação da sociedade.

A FMI, no sentido da indissociabilidade entre educação profissional e educação básica, parte do reconhecimento da necessidade do acesso da camada trabalhadora da sociedade ao trabalho, contudo vislumbra na integração entre o ensino técnico e o ensino médio como possibilidade profícua de garantir a inserção da formação intelectual (cultural, científica, etc.) à formação profissional dos estudantes. Não cabe aqui vislumbrarmos qualquer possibilidade de substituição da formação geral pela formação técnica, ou seja, é necessário que o processo de formação se dê a partir do ideal da omnilateralidade.

Por fim, a integração como sendo a integração de conhecimentos gerais e específicos como totalidade remete à integração entres essas categorias de conhecimento para a formação do todo curricular. Neste aspecto é preciso rever a ideia de hierarquização entre os conhecimentos gerais e específicos e direcionarmos o foco para a integração desses conhecimentos na 
compreensão de fenômenos reais. Desse modo, segundo a autora, há a possibilidade de ter o trabalho como princípio educativo, de historicizar os fenômenos e contribuir para a formação dos sujeitos.

São elementos comuns aos sentidos apresentados a presença da análise crítica dos fenômenos, dos aspectos científicos e culturais da formação atrelados ao trabalho e a perspectiva direcionadora da emancipação humana.

\section{Diversidade e Formação Humana Integral}

Analisando a dualidade de classes através das lentes dos estudos da diversidade poderemos identificar aspectos específicos relacionados aos grupos subalternizados que perpassam questões de desigualdade social, muito embora estejam inseridas e influenciadas por este contexto, e que levam à manutenção, na sociedade moderna, de ideias como o "trabalho de homem" e "trabalho de mulher", a baixa representação de minorias em cargos dirigentes (aqui tratados não em sentido numérico, mas sob a perspectiva da desvantagem no jogo das relações de poder) e a estigmatização baseada em arquétipos que direciona as pessoas para segmentos pré-determinados.

Em um contexto formado pela sociedade de classes e permeado por múltiplas identidades, torna-se necessário que tenhamos a noção de que identidade e classe não são categorias opostas e excludentes, mas sim que é necessário repensar a forma como compreendemos e concebemos a identidade no modelo social vigente.

Outra maneira de lidar com a identidade é perceber e explorar sua potência para descrever e particularizar conjuntos específicos de relações e práticas sociais, das quais derivam valores distintos e perspectivas potenciais específicas de compreensão da realidade social. Tratar identidade dessa forma inscreve as possibilidades de (1) desvelar o seu caráter histórico e socialmente determinado, atravessando o véu da naturalização, e (2) convertê-la em instrumento potente de ações políticas anticapitalistas. (Palha, 2019, p. 39).

Ao não rompermos com esse modelo social baseado na dualidade de classes e/ou não reconhecermos e problematizarmos a construção histórica e social das múltiplas identidades, acabamos por produzir outras segregações intra e interclasses, onde os aspectos relacionados ao gênero, ao sexo, à etnia, dentre outros, também se tornam instrumentos de hierarquização e dominação baseados em preceitos morais e culturais. Preceitos estes que não são necessariamente novos, mas sim a reconfiguração de relações históricas de poder e de dominação que se ajustaram aos moldes do sistema capitalista.

As relações sociais de produção são necessárias a existência material de qualquer formação social ou modo de produção, mas os elementos ou os agentes de um modo de produção, especialmente no que diz respeito ao fator crítico do trabalho destes, tem que ser continuamente produzidos e reproduzidos. Althusser argumenta que, cada vez mais nas formações sociais capitalistas, o trabalho não é reproduzido dentro das próprias relações sociais de produção, mas fora delas. Certamente, para ele não se trata apenas de urna reprodução biológica ou técnica, mas também de urna reprodução social e cultural. É produzido no domínio da superestrutura: em instituições como a família e a Igreja. Requer instituições culturais como a mídia, os sindicatos, os partidos políticos etc., que não estão diretamente ligados a produto em si, mas que exercem a função crucial de "cultivar" um certo tipo de trabalho moral ou cultural - aquilo que o modo capitalista moderno de produção requer. (Hall, 2003, p. 171).

Ainda segundo Hall (2003), as instituições de ensino também compõem esse sistema de interações sociais, tendo o papel de produzir trabalhadores com habilidades técnicas necessárias ao sistema produtivo. Contudo, é necessário que a formação técnica desses trabalhadores não suplante os interesses do capital, o que gera a necessidade de se garantir o controle dos indivíduos por meio de questões culturais, morais e ideológicas convergentes com esse modelo de produção.

Para Durkheim (2016), precursor no estudo sociológico da educação, apresenta uma análise na qual a sociedade e a educação apresentam uma relação intrínseca, sendo a primeira demandante da segunda porquanto produtora de condições para sua manutenção na conformação vigente, de modo que quaisquer variações na composição social impliquem em alterações no 
processo educacional. Para esse autor a sociedade prescinde de homogeneidade para sua manutenção e a educação surge enquanto ferramenta de preparação das novas gerações para se adequarem aos modelos de produção de suas próprias existências.

Direcionando a análise para a escola, percebemos que muitas vezes ela assume um papel reprodutivista das estruturas sociais e, por conseguinte, das desigualdades. Ao recorrermos à análise histórica de como tem se dado sua atuação, podemos identificar que ela

[...] exerceu uma ação distintiva. Ela se incumbiu de separar os sujeitos - tornando aqueles que nela entravam distintos dos outros, os que a ela não tinham acesso. Ela dividiu, também, internamente, os que lá estavam, através de múltiplos mecanismos de classificação, ordenamento, hierarquização. A escola que nos foi legada pela sociedade ocidental moderna começou por separar adultos de crianças, católicos e protestantes. Ela também se fez diferente para os ricos e para os pobres e ela imediatamente separou os meninos das meninas. (Louro, 2014, p. 61).

Após a universalização do acesso à escola, ela passou por uma série de transformações, tendo de se adequar à nova realidade. Segundo Louro (2014, p. 61) “os novos grupos foram trazendo transformações à instituição. Ela precisou ser diversa: organização, currículos, prédios, docentes, regulamentos, avaliações iriam, explícita ou implicitamente, "garantir” - e também reproduzir - as diferenças dos sujeitos".

Essa escola "diversa" não soube lidar com as diferenças, tendo assumido o seu caráter disciplinador - na concepção foucaultiana - em detrimento à escola emancipadora, repreende os comportamentos destoantes dos "padrões normais", controla os corpos e assume a estética branca como modelo. As desigualdades historicamente construídas, simploriamente travestidas de "diferenças", continuam a ser reproduzidas no âmbito escolar sem que haja a preocupação inquisitória quanto às suas produções.

Torna-se claro que enquanto essa escola não vier a romper com esse modelo reprodutivista das desigualdades sociais e venha a assumir uma postura crítica e ativa em busca da emancipação dos sujeitos, onde a diversidade e as diferenças não sejam artificialmente valorizadas e esvaziadas em seus significados, a formação dos educandos não se dará por completa. Defendemos, ainda, que essa ruptura se dê a partir da adoção da FMI como concepção norteadora e que a diversidade e as diferenças sejam contempladas como elementos balizadores de estratégias didático-pedagógicas das instituições escolares. Como consequência dessa ruptura, poderemos acessar novas formas de conceber e debater a construção das identidades.

Para tanto, partimos da proposta de integração defendida por Ramos (2008, p. 20) que visa "[...] possibilitar às pessoas compreenderem a realidade para além de sua aparência fenomênica", uma vez que essa finalidade vai de encontro à ideia de que a diversidade está envolta em uma série de relações específicas e historicamente construídas. A proposta da autora tem por base dois pressupostos: o caráter histórico-social do homem que intervém na natureza para atender às suas necessidades e que a realidade concreta é um todo, síntese de múltiplas relações. Há, ainda, a existência de um terceiro pressuposto decorrente dos dois anteriores e que é de ordem epistemológica onde o conhecimento decorre de uma produção do pensamento onde há a apreensão das relações que constituem e estruturam a realidade objetiva.

A ideia central é de que esses pressupostos sejam aplicados no ensino médio integrado e corroborem para que seja construído um currículo também integrado e interdisciplinarmente construído. "O currículo integrado organiza o conhecimento e desenvolve o processo de ensino-aprendizagem de forma que os conceitos sejam apreendidos como sistema de relações de uma totalidade concreta que se pretende explicar/compreender.” (Ramos, 2008, p. 22). Ainda segundo a autora:

A interdisciplinaridade, como método, é a reconstituição da totalidade pela relação entre os conceitos originados a partir de distintos recortes da realidade; isto é, dos diversos campos da ciência representados em disciplinas. Isto tem 
como objetivo possibilitar a compreensão do significado dos conceitos, das razões e dos métodos pelos quais se pode conhecer o real e apropriá-lo em seu potencial para o ser humano. (Ramos, 2008, p. 22).

As compreensões de currículo integrado e interdisciplinaridade apresentadas pela autora permitem que, dentre outras situações, a produção do conhecimento seja construída a parte da análise relacional dos fenômenos, sob uma abordagem multifocal e das partes para o todo. Pois bem, como já apresentado no texto, a diversidade é justamente um conjunto de partes, construídas historicamente, mediadas por relações de poder e atomizadas em diferenças. Nesse aspecto, a FMI, por meio de um currículo integral e interdisciplinarmente construído, tem muito a contribuir para a compreensão fenomênica da diversidade e, a partir disso, a possibilidade de intervenções na realidade concreta visando a superação das desigualdades. A sedimentação da compreensão de como as diferenças e a diversidade são construídas, altera a compreensão da sociedade como um todo.

Ao se conceber a sociedade atravessada por múltiplas relações de poder, fica absolutamente impossível atuar de cima ou de fora dessa rede. A/o nova/o intelectual terá, necessariamente de se perceber como participando das relações de poder e isso implicará no exercício constante da autocrítica. Atenta/o às "manobras", às "táticas", às "técnicas" e aos "funcionamentos" de produção e de nomeação das desigualdades, a/o intelectual precisará descobrir formas de interferir mais viáveis e próximas. As lutas se tornam mais imediatas e cotidianas. Elas são, também, mais localizadas e talvez pareçam menos ambiciosas. (Louro, 2014, p. 127).

Ainda segundo Louro (2014, p. 128):

A ambição pode ser "apenas" subverter os arranjos tradicionais de gênero na sala de aula: inventando formas novas de dividir os grupos para jogos ou para os trabalhos; promovendo discussões sobre as representações encontradas nos livros didáticos ou nos jornais, revistas e filmes consumidos pelas/os estudantes; produzindo novos textos, não sexistas e não racistas; investigando novos grupos e sujeitos ausentes nos relatos da História oficial, nos textos literários, nos "modelos" familiares; acolhendo no interior da sala de aula as culturas juvenis, especialmente em suas construções sobre gênero, sexualidade, etnia, etc. aparentemente circunscritas ou limitadas a práticas escolares particulares, essas ações podem contribuir para perturbar certezas, para ensinar a crítica e autocrítica (um dos legados mais significativos do feminismo), para desalojar hierarquias.

A escola, enquanto ambiente diverso e de múltiplas interações e relações, pode apresentar uma ampla possibilidade de intervenções imediatas que visem a dirimir a produção das desigualdades, para isso é necessário que assuma o compromisso emancipatório para com seus estudantes, sendo a FMI uma base filosófica e ideológica norteadora totalmente compatível e convergente para o alcance desse fim.

\section{Considerações Finais}

Se, como vimos, a perspectiva da Formação Humana Integral se propõe a alcançar a emancipação humana e essa, por sua vez, se dá na totalidade das relações e interações sociais onde a vida é produzida, não há o que se obstar em relação ao entendimento de que a diversidade e as diferenças estão presentes dentro do escopo da "totalidade das relações sociais". Por consequência, é necessária a compreensão de como os processos de "produção das diferenças" ajuda a compor a diversidade social. A partir de uma perspectiva histórico-crítica os indivíduos poderão compreender que esses processos são permeados por relações de poder e que, mais do que as diferenças em si, são eficientes produtores de desigualdades. Essa compreensão holística dos fenômenos que envolvem a produção de identidade e diferenças torna-se, portanto, elemento essencial para a formação dos sujeitos em sua integralidade.

A compreensão histórica das diversidades significa perceber, por exemplo, que o machismo, a misoginia e a homofobia têm sua gênese em elementos comuns de aversão ao feminino e subversão dos seus papéis pré-determinados 
socialmente. Significa compreender que o racismo tem seu cerne nas antigas civilizações e em suas relações de colonização e dominação com os povos dominados. Significa, ainda, identificar que todos esses fenômenos tem atravessado os séculos, se manifestando através do controle dos corpos e comportamentos, mediados por valores morais que vislumbram, acima de tudo, a manutenção da hegemonia dos padrões vigentes onde o homem, branco e heterossexual ocupa o topo da hierarquia social. É identificar, contemporaneamente, como o neoliberalismo se apropriou destes conceitos, esvaziando-os em significado de forma a garantir a ampliação de seus mercados.

Para tanto, é necessário que a forma de se encarar a diversidade e a diferença seja ressignificada, historicizada e contextualizada, interdisciplinarmente, de modo que os educandos reconheçam como as diferenças são construídas, que a diversidade, muito embora seja inerente à dinâmica social, é permeada por relações de poder e de desigualdade que vão além das relações sociais de produção, inserindo-se em toda estrutura da visa social.

Sugerimos, por fim, que em futuros trabalhos sejam aprofundadas as discussões sobre a evolução da abordagem da diversidade na educação, uma vez que a dinâmica da sociedade reflete diretamente na forma como a escola lida com as diferenças em seu espaço. Essa evolução pode ser investigada, por exemplo, a partir das teorias críticas do currículo que, a despeito de sua centralidade na dinâmica de classes da sociedade capitalista, passou a admitir e debater outros mecanismos que atuam sobre a transformação social e que influenciaram diretamente as ideias que hoje são postas em posição de destaque nas teorias pós-críticas do currículo.

\section{Referências}

Abramowicz, A., Rodrigues, T. C., \& Cruz, A. C. J. d. (2011). A diferença e a diversidade na educação. Contemporânea - Revista de Sociologia da UFSCar, (2), 85-97. https://www.contemporanea.ufscar.br/index.php/contemporanea/article/view/38/20

Butler, J. (2021). Problemas de gênero: feminismo e subversão da identidade (21a ed.). Civilização Brasileira.

Ciavatta, M. (2005). A formação integrada: A escola e o trabalho como lugares de memória e identidade. Revista Trabalho Necessário, (3). https://doi.org/10.22409/tn.3i3.p6122

Cunha, L. L. N. (2020). A antipolítica de gênero Bolsonaro e suas dinâmicas de violência. Revista de Estudios Brasileños 7(14), 49-61. https://doi.org/10.14201/reb20207144961

Creswell, J. W. (2010). Projeto de Pesquisa: métodos qualitativo, quantitativo e misto (3a ed). Artmed.

Durkheim, E. 2016). Educação e Sociologia EDIPRO.

Facchini, R. (2010). Movimento homossexual no Brasil: recompondo um histórico. Cadernos AEL 10(18/19). https://www.al.sp.gov.br/repositorio/bibliotecaDigital/20788_arquivo.pdf

Facchini, R., Carmo, I. N., \& Lima, S. P. (2020). Movimentos feminista, negro e LGBTI no brasil: sujeitos, teias e enquadramentos. Educ. Soc. (v. 41). https://doi.org/10.1590/ES.230408

Feres Júnior, J., Campos, L.A., Daflon, V. T., \& Venturini, A. C. (2018) O conceito de ação afirmativa. In: Ação afirmativa: conceito, história e debates EDUERJ, 13-25. Sociedade e política collection. https://doi.org/10.7476/9786599036477.0003.

Foucault, M. (2008). Segurança, território, população: Curso dado no Collége de France (2a ed.).

Foucault, M. (2019). História da Sexualidade 1 (9a ed.). Paz e Terra.

Gomes, N. L. (2008). A questão racial na escola: desafios colocados pela implementação da Lei 10.639/03. In: V. M. Candau, \& A. F. Moreira (Orgs). Multiculturalismo: Diferenças Culturais e Práticas Pedagógicas (2a ed). Vozes.

Hall, S. (2003). A questão multicultural. In: L. Sovik (Org). Da diáspora: Identidades e mediações culturais. Editora UFMG.

Hall, S. (2003). Significação, Representação, Ideologia: Althusser e os debates pós-estruturalistas. In: L. Sovik (Org). Da diáspora: Identidades e mediações culturais. Editora UFMG.

Instituto Brasileiro de Geografia e Estatística. (2019). Desigualdades sociais por cor ou raça no Brasil. IBGE: Estudos e Pesquisas - Informação Demográfica e Socioeconômica (n. 41). https://biblioteca.ibge.gov.br/visualizacao/livros/liv101681_informativo.pdf

Louro, G. L. (2014). Gênero, sexualidade e educação (16a ed.). Vozes. 
Research, Society and Development, v. 11, n. 3, e7111326442, 2022

(CC BY 4.0) | ISSN 2525-3409 | DOI: http://dx.doi.org/10.33448/rsd-v11i3.26442

Melo, R. S. (2017). Dominação de gênero e esfera pública na teoria crítica feminista. Revista Ideação 1(36), 166-182. https://doi.org/10.13102/ideac.v1i36.3153

Miguel, L. F. (2021). O mito da "ideologia de gênero" no discurso da extrema direita brasileira. Cadernos Pagu (n. 62). https://doi.org/10.1590/18094449202100620016

Moreira, A. F. B., \& Câmara, M. J. (2003). Reflexões sobre currículo e identidade: implicações para a prática pedagógica. In: L. Sovik (Org). Da diáspora: Identidades e mediações culturais. Editora UFMG.

Moura, D. H. (2013). Ensino médio integrado: subsunção aos interesses do capital ou travessia para a formação humana integral? Educação e Pesquisa, 39(3), 705-720. https://www.revistas.usp.br/ep/article/view/62525/65322

Piovesan, F. (2008). Ações afirmativas no Brasil: desafios e perspectivas. Rev. Estud. Fem 16(3), 887-896. https://doi.org/10.1590/S0104$026 \mathrm{X} 2008000300010$

Palla, A. (2019, outubro). Transfeminismo e construção revolucionária. Margem Esquerda, (33), 38-44.

Prado, M. A., Nogueira, P. H. Q., \& Martins, D. A. (2013). Escola e política do armário na produção e reprodução das hierarquias sexuais no Brasil. In: A. Rodrigues \& M. A. S. C. Barreto. Currículos, gêneros e sexualidades: experiências misturadas e compartilhadas. Vitória, ES: Edufes.

Ramos, M. (2008, maio). Concepção de ensino médio integrado. O Desafio de Construção do Ensino Médio Integrado no Estado do Pará, Pará, Belém, Brasil. Recuperado de http://forumeja.org.br/go/sites/forumeja.org.br.go/files/concepcao_do_ensino_medio_integrado5.pdf)

Reis, T. (2015). Homofobia no ambiente educacional: o silêncio está gritando. Appris.

Rodrigues, T., \& Abramowicz, A. (2013). O debate contemporâneo sobre a diversidade e a diferença nas políticas e pesquisas em educação. Educ. Pesq, 3(1), (pp. 15-30). https://doi.org/doi.org/10.1590/S1517-97022013000100002

Santos, B. de S. (2013). Direitos humanos, democracia e desenvolvimento. In: B. de S. Santos \& M. Chauí (Orgs). Direitos humanos, democracia e desenvolvimento. Cortez.

Scott, P., Lewis, L., \& Quadros, M. (2009). Diversidade, diferença, desigualdade e educação. In: P. Scott, L. Lewis \& M. T. Quadros (Orgs.). Gênero, diversidade $e$ desigualdades na educação: interpretações e reflexões para a formação docente. https://www.ufpe.br/documents/1016303/1020379/gnero+diversidade+e+desigualdade+na+educa_o.pdf

Silvério, V. R. (2005). A (re)configuração do nacional e a questão da diversidade. In. A. Abramowicz \& V. Silvério (Orgs.). Afirmando diferenças: Montando o quebra-cabeça da diversidade na escola. Papirus.

Sousa, J. M. (2015). A questão racial e a desigualdade: A discussão do racismo enquanto escolha pedagógica. In: A. A. Pereira \& W. Costa (Orgs.). Educação e diversidade em diferentes contextos. Pallas.

Woodward, K. (2014). Identidade e diferença: uma introdução teórica e conceitual. In: T. T. da Silva (Org). Identidade e Diferença: a perspectiva dos estudos culturais (15a ed). Vozes. 